\title{
Dystonia in a Patient with Melanoma Metastatic to the Brain Treated with High-Dose Interleukin-2, Radiation Therapy, and Levetiracetam
}

\author{
Varun Sreenivasan Arkadiusz Z. Dudek \\ Division of Hematology, Oncology and Transplantation, University of Minnesota \\ Medical School, Minneapolis, Minn., USA
}

\section{Key Words}

Dystonia - Melanoma - Brain metastasis · High-dose interleukin-2 - Gamma Knife therapy · Levetiracetam

\begin{abstract}
Dystonia has been described as a potential toxicity of radiation therapy. Management of this rare movement disorder is targeted in symptom improvement. We report a case of a 46year-old female patient who developed dystonia during treatment of melanoma metastatic to the brain and discuss potential causes of and therapies for this rare complication.
\end{abstract}

\section{Introduction}

Melanoma commonly metastasizes to the brain where it exhibits aggressive growth. Treatment of melanoma metastatic to the brain often requires radiation therapy, chemotherapy, immunotherapy, biologic therapy, or some combination thereof [1]. The choice of treatment is dependent on the tumor location and number of brain metastasis. Patients undergoing treatment of brain metastasis are susceptible to a variety of neurological side effects. Although rare, movement disorders have been reported in the literature. Here, we report the case of a patient with melanoma metastatic to the brain who developed dystonia after treatment with high-dose interleukin (IL)-2, Gamma Knife therapy, and levetiracetam. 


\section{Case Presentation}

A 46-year-old woman with a history of stage IA melanoma of the back presented with shortness of breath. Her medical history included a wide excisional biopsy of a $0.7-\mathrm{mm}$ thick melanoma lesion without ulceration. The sentinel lymph node biopsy revealed no metastatic involvement. Thirteen years later, the patient developed shortness of breath. A computed tomography (CT) scan showed a mediastinal mass above the left pulmonary artery and aortic arch. A positron emission tomography/CT (PET/CT) scan confirmed the presence of a highly metabolically active tumor at the site (fig. 1a). There was no evidence of malignancy elsewhere in the body. One month later, the pathologic mediastinal lymph node was excised and a histological analysis of the removed tissue confirmed BRAF V600E mutated metastatic melanoma. In addition, a magnetic resonance imaging (MRI) scan revealed a tiny focus of enhancement located in the right frontal lobe near the vertex right of the midline. No edema was associated with the lesion. The patient was started on treatment with high-dose IL-2. After 5 doses of IL-2 during cycle 1, the patient developed expected toxicity of pulmonary edema. She recovered completely from the toxicities of the first cycle of therapy, and 21 days after cycle 1 she was admitted for the second cycle of high-dose IL-2. After 6 doses of IL-2 during cycle 2, the patient developed a pulmonary embolus and was treated with lowmolecular-weight heparin. A follow-up PET/CT scan showed resolution of the metastatic disease in the chest (fig. 1b). However, a follow-up brain MRI scan showed that the previously detected lesion was increasing in size (fig. 2a). The patient underwent Gamma Knife therapy 4 months after the second cycle of high-dose IL-2.

Several weeks following this procedure, the patient developed a strange taste in her mouth and noticed that her left hand was clenching and her left foot turning inwards. This episode lasted for about $15 \mathrm{~s}$, and she was started on antiepileptic treatment with levetiracetam. However, she had a second similar episode 1 month later. Electroencephalography showed occasional right hemispheric and frontotemporal slowing. The serum levetiracetam level was suboptimal $(12.8 \mu \mathrm{g} / \mathrm{ml})$. Subsequently, she was given a loading dose of levetiracetam $(1,500 \mathrm{mg})$ and was then put on maintenance therapy with the same drug at 2,000 $\mathrm{mg}$ b.i.d. A 5-day electroencephalography showed no sign of seizure activity. Nevertheless, she developed involuntary movements of the limbs and head 2 months later and subsequently underwent a neurological evaluation.

Physical examination revealed a normal mental status. The neck assumed a mild torticollic posture at times, and while the patient tried to speak, her voice became strained. There was also a slight degree of dystonic posturing of the mouth, and her left hand often assumed a clawed posture. She had minor athetotic movements of the left hand with similar movements in the right hand, albeit of a lesser degree. Her muscle tone and strength were normal. Rapid alternating movements were slower in the left hand than in the right hand. On walking, it was noticed that she bent her knees and walked with a slightly wide gait. The patient was referred to a movement disorder clinic where a more detailed neurological evaluation was performed. This evaluation revealed a normal voluntary gaze. With arms outstretched, no prominent dystonic posturing was noticed, no evidence of appendicular apraxia or ataxia was seen in any limb, and finger-nose-finger tests were normal. There was no evident exaggeration or diminution of reflexes. The gait was abnormal with hyperextension of the back when walking. The left foot rose higher than the right foot, and the gait, in general, appeared to be stiff. Arm swing was preserved with a mild dystonic posturing bilaterally.

The patient was diagnosed with asymmetric generalized dystonia. Paraneoplastic syndrome was considered, and cerebrospinal fluid (CSF) analysis and autoimmune blood tests 
were ordered. CSF analysis showed that the IgG level was $1.9 \mathrm{mg} / \mathrm{dl}$ (reference: <8.1), glucose $45 \mathrm{mg} / \mathrm{dl}$, total protein $33 \mathrm{mg} / \mathrm{dl}$, and albumin $19.2 \mathrm{mg} / \mathrm{dl}$. No oligoclonal bands were seen in the CSF analysis. Titers for ANNA proteins, ampiphysin, and CRMP-5-IgG were negative in CSF. Serum IgG was $868 \mathrm{mg} / \mathrm{dl}$ (reference range: 767-1,590), and serum ceruloplasmin was $21 \mathrm{mg} / \mathrm{dl}$ (reference range: 20-60). Serum protein electrophoresis showed no monoclonal proteins, and autoimmune panel testing for TPO antibodies, rheumatoid factor, myeloperoxidase, ganglionic AChR antibodies, ANNA proteins, CRMP-5IgG, calcium channel antibodies, and neuronal channel antibodies were negative. Antinuclear antibody was weakly positive at $2.6 \mathrm{IU} / \mathrm{ml}$ and the TSH level was $2.2 \mathrm{mIU} / \mathrm{ml}$. One month later, repeat serum analysis showed the presence of $\operatorname{IgA}(129 \mathrm{mg} / \mathrm{dl}), \operatorname{IgG}(905 \mathrm{mg} / \mathrm{dl})$, and $\operatorname{IgM}(80 \mathrm{mg} / \mathrm{dl})$. After these tests, it was noticed that the patient had vitiligo. Though the autoimmune panel was mostly negative, an autoimmune process causing the patient's current symptoms was not ruled out given the presence of vitiligo.

Levetiracetam was stopped because of the absence of new seizures. Thereafter, in the assumption of an autoimmune process responsible for dystonia, either steroid or intravenous immunoglobulin therapy was proposed. Intravenous immunoglobulin was started, but the patient developed an allergic reaction with a burning sensation in the hands and neck as well as skin erythema. At the same time, her dystonia worsened, for which she was treated with $1 \mathrm{~g}$ methylprednisolone. Although the patient developed an allergic reaction to methylprednisolone, it was controlled with diphenhydramine. Her dystonia is currently improving without additional therapy. Serial imaging scans have not shown any evidence of melanoma recurrence, however (fig. $2 \mathrm{~b}, \mathrm{c}$ ).

\section{Discussion}

Dystonia is a neurologic disorder characterized by involuntary, sustained, patterned, and often repetitive muscular contractions of opposing muscles that cause twisting movements, abnormal postures or both [2]. Dystonia is associated with mutations in more than 30 different genes and is a feature of several neurodevelopmental or neurodegenerative disorders. Dystonia can arise from a vast array of acquired insults to the nervous system and may occur as primary dystonia, dystonia-plus syndromes, as part of developmental or degenerative disorders, or as acquired insults. From a pathophysiological perspective, it has been assumed that most dystonias arise from a dysfunction of the basal ganglia. However, this is not an absolute requirement [3].

Depending on the number of brain metastasis, radiation can be given as stereotactic radiosurgery or whole-brain radiation therapy. Stereotactic radiosurgery has been shown to be associated with fewer side effects. In a study by Hong et al. [4] on 253 patients receiving stereotactic radiosurgery with no prior treatment for metastasis, acute side effects were noted in 95 patients. In decreasing frequency, these side effects were headache (17), seizures (11), fluid retention (7), and neurological changes (7) [4]. In another study by Williams et al. [5] on 316 patients, the most common long-term complications in decreasing frequency were seizures $(13 \%)$, hydrocephalus, and hemorrhage. Motor deficits were seen in $8 \%$, visual deficits in $4 \%$, sensory deficits in $3 \%$, and cognitive deficits in $9 \%$. However, the authors did not report any movement disorders. Two case reports have mentioned the development of movement disorders in patients receiving Gamma Knife therapy. The first one is by Chiou et al. [6], reporting a 20-year-old patient who developed Holmes tremor after receiving Gamma Knife treatment for arteriovenous malformation. It was strongly suspected that, in this case, focal edema or infarction caused by obliteration of penetrating arteries due 
to application of Gamma Knife radiation triggered a disruption of the cerebellorubrothalamic circuitry, and thereby tremor [6]. A similar cause was possible in our patient given the location of the lesion and the known association between basal ganglia dysfunction and dystonia. The second case report referring to movement disorders in patients receiving Gamma Knife therapy is by Chung et al. [7] who describe a patient developing isolated tremor of the tongue following Gamma Knife treatment for acoustic schwannoma .

On the other hand, high-dose IL-2 is an established therapy for brain metastasis in both kidney cancer and melanoma. However, its usefulness is limited due to toxicity, which in most cases resembles bacterial sepsis. Toxicity has been shown to be mediated by secondary cytokines such as TNF-alpha. Most of these effects are transient and reversible while the patient is under observation [8]. In a retrospective study by Guirguis et al. [9], 1,069 patients with a history of brain metastasis were studied after receiving high-dose IL-2. The most common side effects noted were disorientation and alteration in the level of consciousness. These effects were reversible once the treatment was stopped. Previous case reports have documented the reactivation of psoriasis and rheumatoid arthritis in patients receiving highdose IL-2 therapy. Kinkel et al. [10] reported the rapid neurological deterioration in a patient with a history of multiple sclerosis receiving systemic IL-2 and interferon-alpha therapy. A CSF analysis revealed an increased IgG synthesis without pleocytosis or evidence of a bloodbrain barrier breakdown. It was proposed that the neurological deterioration was due to IL2 -induced, focally accelerated, immune-mediated demyelination, without formation of new plaques. The IL-2 therapy may have accelerated the process. This observation suggests that an immune-mediated mechanism could have been involved in the development of dystonia in our patient, especially given the development of vitiligo, and Il-2 therapy could have accelerated this process.

Levetiracetam has been used for the treatment of dystonia [11]. Though its efficacy has been questioned [12], we have been unable to find any literature attributing the development of dystonia to levetiracetam therapy. The neurological side effect profile of levetiracetam comprises mainly somnolence, asthenia, and dizziness. Other significant side effects are related to psychiatric symptoms such as irritability, aggression, hostility, and hallucinations [13].

It should also be noted that the enhancing lesion seen in the MRI scan could be a cause of the symptoms faced by the patient. However, given the bilateral nature of the symptoms and the generalized involvement of the body, this is extremely unlikely.

In conclusion, we have found this case to be unique considering the de novo development of dystonia with no previous history of similar disorders. An autoimmune mechanism is strongly suspected given the presence of vitiligo and IL-2 treatment. However, as shown in other reported cases, Gamma Knife therapy can equally cause these symptoms. The absence of conclusive serological evidence of an autoimmune mechanism gives further credence to the Gamma Knife theory. We suggest that close monitoring and neurological assessment is warranted in patients receiving IL-2 and Gamma Knife therapies on a regular basis. Such data is expected to provide insight into the possible mechanisms underlying the development of dystonia.

\section{References}

1 Hong WK, Bast RC, Hait WN, Kufe DW, Pollock RE, Weichselbaum RR, Holland JF, Frei E (eds): Cancer Medicine, ed 8. New York, PMPH Publishing House, 2010, p 1484.

2 Jankovic J: Dystonia. New York, Demos Medical Publishing, 2005. 


\section{Case Reports in Oncology}

\begin{tabular}{|c|c|}
\hline \multicolumn{2}{|c|}{ Case Rep Oncol 2013;6:78-83 } \\
\hline DOI: $\underline{10.1159 / 000346932}$ & $\begin{array}{l}\text { (C) } 2013 \text { S. Karger AG, Basel } \\
\text { www.karger.com/cro }\end{array}$ \\
\hline
\end{tabular}

Sreenivasan et al.: Dystonia in a Patient with Melanoma Metastatic to the Brain Treated with High-Dose Interleukin-2, Radiation Therapy, and Levetiracetam

3 Neychev VK, Gross RE, Lehéricy S, Hess EJ, Jinnah HA: The functional neuroanatomy of dystonia. Neurobiol Dis 2011;42:185-201.

4 Hong TS, Tome WA, Hayes L, Yuan Z, Badie B, Rao R, Mehta MP: Acute Sequelae of Stereoatactic Radiosurgery. Radiosurgery: 6th International Stereotactic Radiosurgery Society Meeting, Kyoto, June 2226, 2003. Basel, Karger Publishers, 2004, p 38.

5 Williams BJ, Suki D, Fox BD, Pelloski CE, Maldaun MV, Sawaya RE, Lang FF, Rao G: Stereotactic radiosurgery for metastatic brain tumors: a comprehensive review of complications. J Neurosurg 2009;111:439-448.

6 Chiou TS, Tsai CH, Lee YH: Unilateral Holmes tremor and focal dystonia after Gamma Knife surgery. J Neurosurg 2006;105(suppl):235-237.

7 Chung SJ, Im JH, Lee JH, Cho AH, Kwon M, Lee MC: Isolated tongue tremor after gamma knife radiosurgery for acoustic schwannoma. Mov Disord 2005;20:108-111.

8 DeVita VT, Lawrence TS, Rosenberg SA (eds): DeVita, Hellman, and Rosenberg's Cancer: Principles and Practice of Oncology. Philadelphia, Lippincott Williams \& Wilkins, 2008, p 510.

$\$ 9$ Guirguis LM, Yang JC, White DE, Steinberg SM, Liewehr DJ, Rosenberg SA, Schwartzentruber DJ: Safety and efficacy of high-dose interleukin-2 therapy in patients with brain metastases. J Immunother 2002;25:82-87.

10 Kinkel RP, Rudick RA, Ransohoff RM: Rapid neurological deterioration in a patient with multiple sclerosis treated with systemic interleukin-2 and interferon-alpha $2 \mathrm{~b}$ for metastatic renal cell carcinoma. J Neurol Neurosurg Psychiatry 1997;62:100.

11 Sullivan KL, Hauser RA, Louis ED, Chari G, Zesiewicz TA: Levetiracetam for the treatment of generalized dystonia. Parkinsonism Relat Disord 2005;11:469-471.

12 Hering S, Wenning GK, Seppi K, Poewe W, Mueller J: An open trial of levetiracetam for segmental and generalized dystonia. Mov Disord 2007;22:1649-1651.

13 Shorvon SD, van Rijckevorsel K: A new antiepileptic drug. J Neurol Neurosurg Psychiatry 2002;72:426-429.
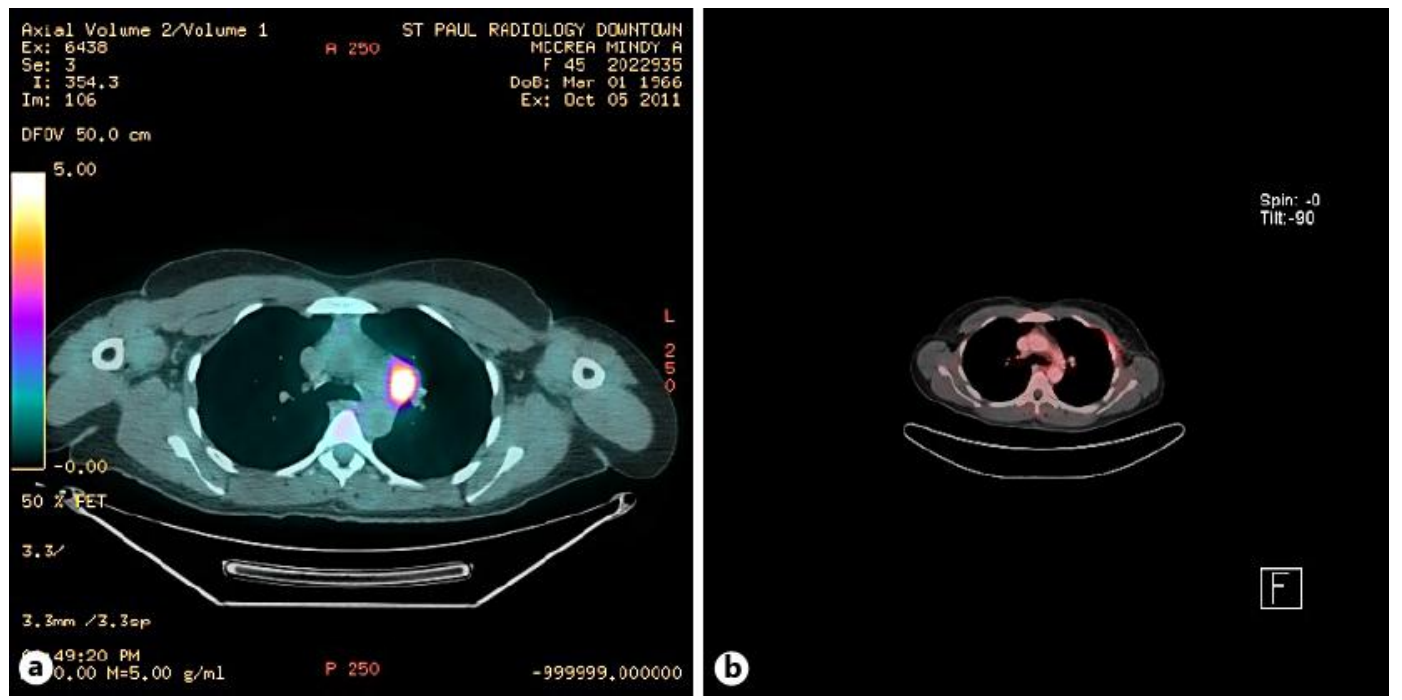

Fig. 1. A PET scan showing a mediastinal mass before IL-2 therapy (a) and the same area without the mass after IL-2 therapy (b). 


\section{Case Reports in Oncology}

\begin{tabular}{l|l}
\hline Case Rep Oncol 2013;6:78-83 & \\
\hline DOI: $\underline{10.1159 / 000346932}$ & $\begin{array}{l}\text { @ 2013 S. Karger AG, Basel } \\
\text { www.karger.com/cro }\end{array}$ \\
\hline
\end{tabular}

Sreenivasan et al.: Dystonia in a Patient with Melanoma Metastatic to the Brain Treated with High-Dose Interleukin-2, Radiation Therapy, and Levetiracetam
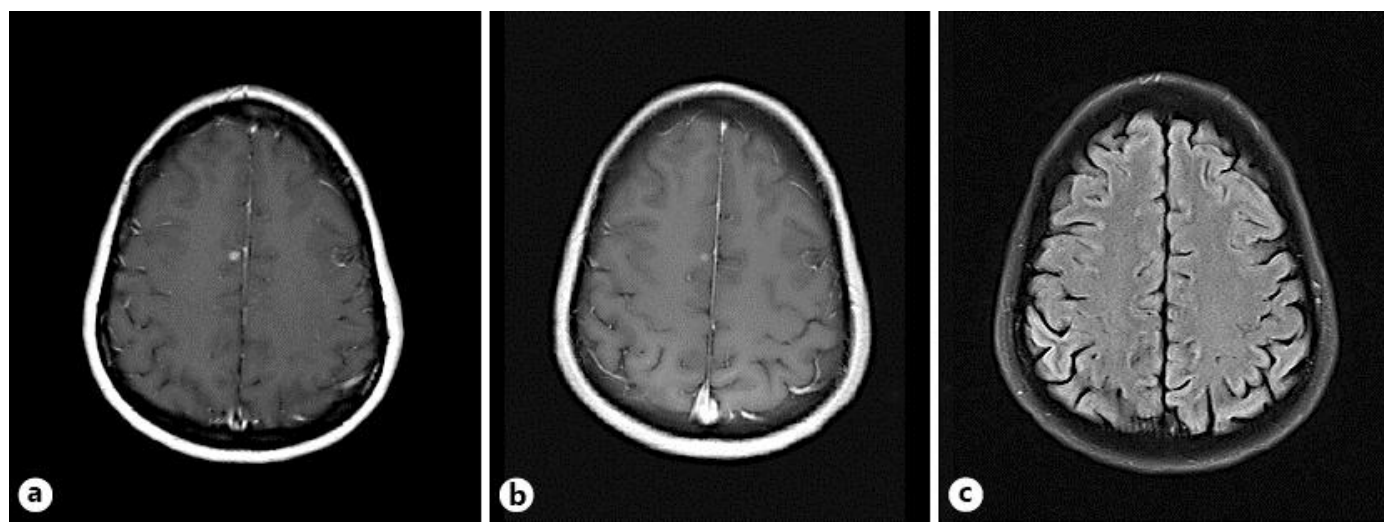

Fig. 2. A brain MRI scan showing an enhancing lesion before Gamma Knife therapy (a) and the same area 3 months (b) and 5 months (c) after Gamma Knife therapy. 